\title{
Probabilistic risk assessment of abalone Haliotis diversicolor supertexta exposed to waterborne zinc
}

\author{
Chung-Min Liao*, Min-Pei Ling \\ Department of Bioenvironmental Systems Engineering, National Taiwan University, Taipei, Taiwan 10617, ROC
}

Received 7 May 2003; accepted 1 August 2003

"Capsule": A novel risk assessment method was developed for abalone.

\begin{abstract}
This paper describes a risk assessment approach that integrates predicted tissue concentrations of zinc (Zn) with a concentrationresponse relationship and leads to predictions of survival risk for pond abalone Haliotis diversicolor supertexta as well as to the uncertainties associated with these predictions. The models implemented include a probabilistic bioaccumulation model, which linking biokinetic and consumer-resource models, accounts for $\mathrm{Zn}$ exposure profile and a modified Hill model for reconstructing a dose-response profile for abalone exposed to waterborne $\mathrm{Zn}$. The growth risk is assessed by hazard quotients characterized by measured water level and chronic no-observed effect concentration. Our risk analyses for $H$. diversicolor supertexta reared near Toucheng, Kouhu, and Anping, respectively, in north, central, and south Taiwan region indicate a relatively low likelihood that survival is being affected by waterborne $\mathrm{Zn}$. Expected risks of mortality for abalone were estimated as 0.46 (Toucheng), 0.36 (Kouhu), and 0.29 (Anping). The predicted 90th-percentiles of hazard quotient for potential growth risk were estimated as 1.94 (Toucheng), 0.47 (Kouhu), and 0.51 (Anping). These findings indicate that waterborne $\mathrm{Zn}$ exposure poses no significant risk to pond abalone in Kouhu and Anping, yet a relative high growth risk in Toucheng is alarming. Because of a scarcity of toxicity and exposure data, the probabilistic risk assessment was based on very conservative assumptions.
\end{abstract}

(C) 2003 Elsevier Ltd. All rights reserved.

Keywords: Abalone; Probabilistic; Risk assessment; Zinc

\section{Introduction}

Abalone, Haliotis diversicolor supertexta, is the most abundant abalone species in Taiwan. $H$. diversicolor supertexta is commercially important for fisheries and aquaculture in Taiwan (Chen, 1989). H. diversicolor supertexta are appreciated for their delicacy and high market value; therefore, the aquaculture of $H$. diversicolor supertexta is a promising business (Chen 1989; Singhagraiwan and Doi 1993). Abalone were readily identifiable and can be sampled easily. Their biological and ecological characteristics are known, they strongly accumulate pollutants, and they can be easily reared both in the laboratory and commercially (Hahn, 1989). However, the coastal regions of Taiwan where the abalone aquaculture facilities are located are subjected to polluted discharges from rivers.

* Corresponding author. Tel.: + 886-2-2363-4512; fax: + 886-22362-6433.

E-mail address: cmliao@ccms.ntu.edu.tw (C.-M. Liao).
Zinc $(\mathrm{Zn})$ is an essential micronutrient found at high level in the tissues of gastropods mollusks (Lin and Liao, 1999; Richardson, 2001; Wang and Ke, 2002). Zn is available to abalone from both the dissolved phase (e.g., gill uptake) and the diet (e.g., algae ingestion). If waterborne $\mathrm{Zn}$ levels are elevated, toxicity can occur and has severe effects on the health of abalone, which will reduce market prices and cause closure of abalone farms (Hahn, 1989; Conroy et al., 1996; Knauer et al., 1997). Previous investigations indicated that $\mathrm{Zn}$ have been detected in many rivers in that maximum $\mathrm{Zn}$ concentrations in aquaculture waters are reported to range from 60 to $300 \mathrm{ng} \mathrm{ml}^{-1}$ in different areas of Taiwan (Lin and Liao, 1999; Liao et al., 2002a). Because few previous studies have evaluated $\mathrm{Zn}$ toxicity to $H$. diversicolor supertexta, the mechanisms involved in the inhibition of growth remain unknown.

Zinc was chosen for practical as well as theoretical reasons with the availability of reasonable amounts of suitable information as the primary consideration. Generally, as prerequisites for data suitability, we 


\section{Nomenclature}

\begin{tabular}{|c|c|}
\hline$A$ & Steady-state algae biomass $\left(\mathrm{g}^{-1}\right)$ \\
\hline$A(t)$ & Algae biomass as a function of time $t\left(\mathrm{~g} \mathrm{l}^{-1}\right)$ \\
\hline$B$ & Steady-state abalone biomass $\left(\mathrm{g} \mathrm{1}^{-1}\right)$ \\
\hline$B(t)$ & Abalone biomass as a function of time $t\left(\mathrm{~g}^{-1}\right)$ \\
\hline $\mathrm{BCF}_{a}$ & Bioconcentration factor for algae $\left(\mathrm{ml} \mathrm{g}^{-1}\right)$ \\
\hline $\mathrm{BMF}_{m}$ & Biomagnification factor for abalone $\left(\mathrm{g} \mathrm{g}^{-1}\right)$ \\
\hline $\mathrm{BCF}_{m}$ & Bioconcentration factor for abalone $\left(\mathrm{ml} \mathrm{g}^{-1}\right)$ \\
\hline$C_{a}$ & Steady-state $\mathrm{Zn}$ concentration in algae ( $\mu \mathrm{g} \mathrm{g}^{-1}$ dry wt.) \\
\hline$C_{a}(t)$ & Time-dependent $\mathrm{Zn}$ concentration in algae ( $\mu \mathrm{g} \mathrm{g}^{-1}$ dry wt.) \\
\hline$C_{L, 50}$ & Internal effect concentration at the site of action that cause $50 \%$ mortality ( $\mu \mathrm{g} \mathrm{g}^{-1}$ dry wt.) \\
\hline $\mathrm{C}_{m}$ & Steady state $\mathrm{Zn}$ concentration in abalone soft tissue ( $\mu \mathrm{g} \mathrm{g}^{-1}$ dry wt.) \\
\hline $\mathrm{C}_{m}(t)$ & Time-dependent $\mathrm{Zn}$ concentration in abalone soft tissue ( $\mu \mathrm{g} \mathrm{g}^{-1}$ dry wt.) \\
\hline $\bar{C}_{m}$ & Mean concentration of $\mathrm{Zn}$ in abalone soft tissue $\left(\mu \mathrm{g} \mathrm{g}^{-1}\right)$ \\
\hline$C_{w}$ & Dissolved $\mathrm{Zn}$ concentration in water $\left(\mu \mathrm{g} \mathrm{ml}^{-1}\right)$ \\
\hline$D$ & Half-saturation for algae ingestion $\left(\mathrm{g}^{-1}\right)$ \\
\hline $\mathbf{E}[\bullet]$ & Expectation operator \\
\hline $\mathbf{E}[R]$ & Expected risk \\
\hline $\mathrm{EC}_{10}$ & Effective concentration that causes $10 \%$ effect $\left(\mu \mathrm{g} \mathrm{g}^{-1}\right)$ \\
\hline $\mathrm{EC}_{50}$ & Median effective concentration $\left(\mu \mathrm{g} \mathrm{g}^{-1}\right)$ \\
\hline$f$ & Biomass conversion rate for algae ingested by abalone $\left(\mathrm{g} \mathrm{g}^{-1}\right)$ \\
\hline$F\left(C_{m}\right)$ & Cumulative distribution function (cdf) of having abalone tissue $\mathrm{Zn}$ concentration \\
\hline$F\left(\bar{C}_{m}\right)$ & Cdf of having mean $\mathrm{Zn}$ concentration in abalone soft tissue \\
\hline$F(M \mid C)$ & Cdf of predicted mortality function for a given tissue $\mathrm{Zn}$ concentration \\
\hline$F\left(M \mid C_{\mathrm{m}}\right)$ & Conditional cdf of the mortality at given tissue $\mathrm{Zn}$ concentration \\
\hline$F\left(M \mid \bar{C}_{\mathrm{m}}\right)$ & Conditional cdf of the mortality at given mean $\mathrm{Zn}$ concentration in abalone soft tissue \\
\hline$g$ & Grazing rate of abalone $\left(\mathrm{g} \mathrm{g}^{-1} \mathrm{day}^{-1}\right)$ \\
\hline $\mathrm{HQ}$ & Hazard quotient \\
\hline$K$ & Algae carrying capacity $\left(\mathrm{g}^{-1}\right)$ \\
\hline$k_{1}$ & Uptake rate constant from dissolved $\mathrm{Zn}$ by abalone $\left(\mathrm{ml} \mathrm{g}^{-1} \mathrm{day}^{-1}\right)$ \\
\hline$k_{1 \mathrm{a}}$ & Uptake rate constant from dissolved $\mathrm{Zn}$ by algae $\left(\mathrm{ml} \mathrm{g}^{-1} \mathrm{day}^{-1}\right)$ \\
\hline$k_{2}$ & Depuration rate constant for $\mathrm{Zn}$ in abalone $\left(\mathrm{day}^{-1}\right)$ \\
\hline$k_{2 \mathrm{a}}$ & Depuration rate constant for $\mathrm{Zn}$ in algae $\left(\mathrm{day}^{-1}\right)$ \\
\hline $\mathrm{LC}_{50}$ & Median lethal concentration $\left(\mathrm{mg} \mathrm{1}^{-1}\right)$ \\
\hline $\mathrm{LC}_{50}(\infty)$ & Incipient median lethal concentration $\left(\mathrm{mg} \mathrm{l}^{-1}\right)$ \\
\hline $\mathrm{LN}_{C_{m}}$ & Lognormal probability density function (pdf) of having tissue $\mathrm{Zn}$ concentration \\
\hline$M$ & Mortality (\%) \\
\hline NOEC & Chronic no-observed effect concentration of toxicant reference value \\
\hline PEC & Predicted environmental concentration \\
\hline$r_{a}$ & Growth rate of algae $\left(\mathrm{day}^{-1}\right)$ \\
\hline$R\left(C_{m}\right)$ & Risk at a specific $\mathrm{Zn}$ concentration in abalone \\
\hline$t$ & Time of exposure (day) \\
\hline TRV & Toxicant reference value \\
\hline$\alpha$ & Assimilation efficiency $(\%)$ \\
\hline$\mu_{g}$ & Geometric mean \\
\hline$\sigma_{g}$ & Geometric standard deviation \\
\hline$\mu_{m}$ & Death rate of abalone $\left(\mathrm{day}^{-1}\right)$ \\
\hline$\Phi(\bullet)$ & Cumulative standard normal distribution \\
\hline
\end{tabular}


required exposure and whole-body $\mathrm{Zn}$ levels measured by accepted analytical techniques. In this respect, we considered experimental exposure data to be acceptable only when whole-body concentration data were available and when the exposure duration was at least 14 days. Our previous published $\mathrm{Zn}$-abalone database meet this principle. On the other hand, $\mathrm{Zn}$ was chosen in this study because this represents a metal of general concern in terms of environmental protection and in future study, it can span the continuum from nutritionally essential to nonessential, such as $\mathrm{Pb}$ or $\mathrm{Ag}$.

In this present work, we develop a systematic and quantitative risk assessment framework, which is most needed to interpret the significance of the reported exposures. A major complication in predicting or estimating risks for aquacultural species is the high degree of uncertainty resulting from the lack of dose-response information and the large environmental variability in exposures among individuals. As a result, formal risk assessments are scarce regarding the aquacultural species. We focus on the risk of survival and growth of abalone exposed to waterborne $\mathrm{Zn}$ because evidence for this type of adverse effect has been presented in numerous studies (Lin and Liao, 1999; Liao and Lin, 2001; Liao et al., 2002b; Tsai et al., 2003). Thus, knowledge of the potential risks associated with exposure to $\mathrm{Zn}$ is essential for the effective formulation of conservation and management plans.

The objectives of this study are twofold: (1) to conduct an environmental risk assessment based on the USEPA methodology, and (2) to address the uncertainties by using a probabilistic approach to risk characterization that yields quantitative estimates of the risks themselves and also of their associated uncertainties. We use a bioaccumulation model, which links biokinetics and consumer-resource dynamics, to estimate the tissue $\mathrm{Zn}$ concentrations in abalone. We combine predicted tissue concentration and internal lethal body burden data with a dose-response relationship derived from experimental studies on abalone allowing us to assess survival endpoint. A hazard quotient featuring measured water $\mathrm{Zn}$ level and chronic no-observed effect concentration is used to assess the growth endpoint. To determine overall uncertainty in predicted risks, the uncertainties resulting from the assessments of exposure and dose-response are propagated through the risk characterization process using Monte Carlo analysis.

\section{Materials and methods}

\subsection{Study sites}

The major $\mathrm{Zn}$ exposure data was obtained from the previous studies conducted by Lin and Liao (1999), Liao et al. (2002a,b, 2003). They chose three appropriate management practices on abalone farms for three different study sites situated at Toucheng, Kouhu, and Anping, respectively, in north, central, and south Taiwan region. They measured $\mathrm{Zn}$ concentrations in pond water, algae and soft tissue of abalone and conducted laboratory exposure experiments to estimate the essential biokinetic and physiological parameters in an abalone- $\mathrm{Zn}$ system. The selected nine abalone farms had similar feeding strategies and the biomass of algae and abalone were monitored throughout each growing season by the farm owners.

\subsection{Exposure profile}

We used a first-order two-compartment model considered from the viewpoint of consumer-resource dynamics based on the approach developed by Liao et al. (2002a) to estimate $\mathrm{Zn}$ concentrations in abalone and algae. The scenario (Fig. 1) that we considered is (1) the exchange of $\mathrm{Zn}$ between abalone and dissolved $\mathrm{Zn}$ was modeled as a first-order process, with additional $\mathrm{Zn}$ accumulation from ingested algae, (2) abalone ingest only algae and other suspended particles, bacteria and detritus uptakes are negligible, (3) tissue concentration of $\mathrm{Zn}$ per unit biomass of abalone increases as a result of direct uptake from water and through assimilation of contaminated algae, and (4) tissue concentration tends to decrease as a result of elimination from the whole body and growth dilution.

The first-order two-compartment model for the gain and loss of $\mathrm{Zn}$ accumulation in abalone and algae features constant biokinetic and physiological rates and constant water concentration. Accordingly, the dynamic behavior corresponding to the graphic model of Fig. 1 would be represented as (Liao et al., 2002a),

$$
\begin{aligned}
\frac{\mathrm{d} A(t)}{\mathrm{d} t}= & r_{a}\left(1-\frac{A(t)}{K}\right) A(t)-g\left(\frac{A(t)}{A(t)+D}\right) B(t), \\
\frac{\mathrm{d} B(t)}{\mathrm{d} t}= & f g\left(\frac{A(t)}{A(t)+D}\right) B(t)-\mu_{m} B(t), \\
\frac{\mathrm{d} C_{m}(t)}{\mathrm{d} t}= & \left(k_{1}+\alpha g\left(\frac{A(t)}{A(t)+D}\right) \mathrm{BCF}_{a}\right) C_{w} \\
& -\left(k_{2}+f g\left(\frac{A(t)}{A(t)+D}\right)\right) C_{m}(t),
\end{aligned}
$$

$$
\frac{\mathrm{d} C_{a}(t)}{\mathrm{d} t}=k_{1 a} C_{w}-\left(k_{2 a}+\alpha g\left(\frac{B(t)}{A(t)}\right) \mathrm{BMF}_{m}\right) C_{a}(t),
$$

where $r_{a}$ is the growth rate of algae $\left(\right.$ day $\left.^{-1}\right), K$ is the algae carrying capacity $\left(\mathrm{g}^{-1}\right), A(t)$ is the algae biomass as a function of time $t\left(\mathrm{~g}^{-1}\right), B(t)$ is the abalone 


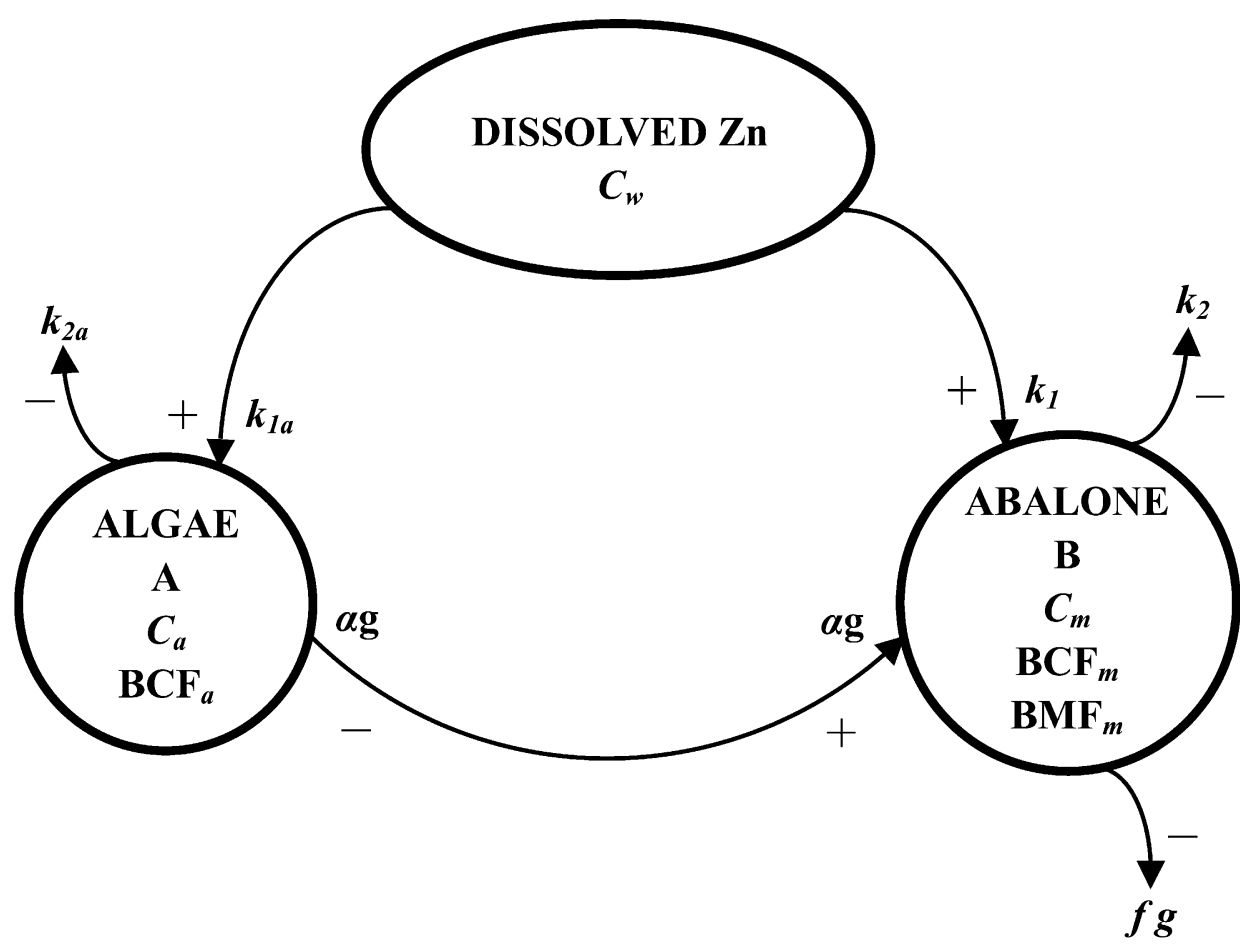

Fig. 1. Schematic showing the first-order two-compartment bioaccumulation model that linking biokinetic and consumer-resource dynamic models to describe $\mathrm{Zn}$ accumulation in abalone H. diversilor supertexta and their food red algae G. tenuisipitata var. lilu [see Eqs. (1)-(4) for full explanation].

biomass as a function of time $t\left(\mathrm{~g} \mathrm{l}^{-1}\right), D$ is the halfsaturation for algae ingestion $\left(\mathrm{g}^{-1}\right), f$ is the biomass conversion efficiency of ingested algae $\left(\mathrm{g} \mathrm{g}^{-1}\right), g$ is the grazing rate of algae by abalone $\left(\mathrm{g} \mathrm{g}^{-1} \mathrm{day}^{-1}\right)$, and $\mu_{m}$ is the abalone death rate $\left(\mathrm{day}^{-1}\right), \mathrm{C}_{m}(t)$ is the timedependent $\mathrm{Zn}$ concentration in abalone soft tissue $(\mu \mathrm{g}$ $\mathrm{g}^{-1}$ dry wt.), $t$ is the time of exposure (d), $C_{w}$ is the dissolved $\mathrm{Zn}$ concentration in water $\left(\mu \mathrm{g} \mathrm{ml}^{-1}\right), k_{1}$ is the uptake rate constant from dissolved phase by abalone $\left(\mathrm{ml} \mathrm{g}^{-1}\right.$ day $\left.^{-1}\right), \alpha$ is the assimilation efficiency of abalone $(\%), \mathrm{BCF}_{\mathrm{a}}$ is the bioconcentration factor for $\mathrm{Zn}$ in algae $\left(\mathrm{ml} \mathrm{g}^{-1}\right), k_{2}$ is the depuration rate constant for $\mathrm{Zn}$ in abalone $\left(\right.$ day $\left.^{-1}\right), C_{a}(t)$ is the time-dependent $\mathrm{Zn}$ concentration in algae $\left(\mu \mathrm{g} \mathrm{g}^{-1}\right.$ dry wt.), $k_{1 \mathrm{a}}$ is the uptake rate constant from dissolved $\mathrm{Zn}$ by algae $\left(\mathrm{ml} \mathrm{g}^{-1}\right.$ $\left.\mathrm{day}^{-1}\right), k_{2 \mathrm{a}}$ is the depuration rate constant for $\mathrm{Zn}$ in algae $\left(\right.$ day $\left.^{-1}\right)$, and $\mathrm{BMF}_{\mathrm{m}}$ is the biomagnification factor for $\mathrm{Zn}$ in abalone $\left(\mathrm{g} \mathrm{g}^{-1}\right)$.

We consider the steady-state condition in Eqs. (1)-(4) and assume $K>>A$ as suggested by Liao et al. (2002a), and solve for $C_{a}$ and $C_{m}$ gives

$$
\begin{aligned}
C_{a} & =\frac{k_{1 a} C_{w}}{k_{2 a}+\alpha g\left(\frac{B}{A}\right) \mathrm{BMF}_{m}}, \\
C_{m} & =\frac{\left(k_{1}+\alpha g\left(\frac{A}{A+D}\right) \mathrm{BCF}_{a}\right) C_{w}}{k_{2}+f g\left(\frac{A}{A+D}\right)},
\end{aligned}
$$

where $B$ and $A$ can also be obtained, respectively, as

$$
\begin{aligned}
& B=\frac{r_{a} A}{g\left(\frac{A}{A+D}\right)}, \\
& A=\frac{\mu_{m} D}{f g-\mu_{m}} .
\end{aligned}
$$

The input variables needed to model the $\mathrm{Zn}$ bioaccumulation in abalone and algae include consumerresource parameters $\left(f, g, \mu_{m}, r_{a}, \alpha, D\right)$, biokinetic parameters $\left(k_{1}, k_{2}, k_{1 \mathrm{a}}, k_{2 \mathrm{a}}, \mathrm{BCF}_{\mathrm{a}}, \mathrm{BMF}_{\mathrm{m}}\right)$, and geochemical variable of $C_{w}$.

\subsection{Concentration-response profile}

Tissue residues and adjusted response frequencies were used to construct a concentration-response relationship for mortality versus $\mathrm{Zn}$ whole-body burden in abalone based on a pharmacodynamic Hill model (Lalonde, 1992; Bourne, 1995). Liao et al. (2002b) have established a quantitative relationship between $\mathrm{Zn}$ tissue residues and mortality effects in abalone. Based on the acute toxicity data, mortality function is estimated from observed mortality percentages in exposure regimes in which mortality is an increasing function of the $\mathrm{Zn}$ concentration in water. In fitting the Hill model to the observed mortality for specific-interval acute toxicity data, the dose-response profile can be expressed as (Liao et al., 2002b), 
$M=\frac{100 \times C_{w}^{3.70}}{\left(24-\mathrm{h} \mathrm{LC}_{50}\right)^{3.70}+C_{w}^{3.70}}$,

where $M$ is the mortality (\%), the exponent 3.70 is an average value of the fitted Hill coefficient and 24-h LC $_{50}$ is the 24-h median lethal concentration $\left(\mathrm{mg} \mathrm{l}^{-1}\right)$.

Eq. (9) can be transformed appropriately to a tissue residue-response relationship using the Hill model framework to predict the response as (Liao et al., 2002b),

$$
\begin{aligned}
M & =\frac{100 \times C_{m}^{3.70}}{\left(C_{L, 50}\right)^{3.70}+C_{m}^{3.70}} \\
& =\frac{100 \times C_{m}^{3.70}}{\left(\mathrm{BCF}_{m} \times \mathrm{LC}_{50}(\infty)\right)^{3.70}+C_{m}^{3.70}},
\end{aligned}
$$

where $C_{L, 50}$ is the internal effect concentration at the site of action that cause $50 \%$ mortality, $\mathrm{BCF}_{\mathrm{m}}$ is the bioconcentration factor of abalone $\left(\mathrm{ml} \mathrm{g}^{-1}\right)$, and $\mathrm{LC}_{50}(\infty)$ is the incipient value of $\mathrm{LC}_{50}(t)$. We treated $\mathrm{BCF}_{m}$ and $\mathrm{LC}_{50}(\infty)$ in Eq. (10) probabilistically. Applying the Hill model, the cumulative distribution function (cdf) of predicted mortality function for a given tissue $\mathrm{Zn}$ concentration, $F(M \mid C)$, could be expressed symbolically as a conditional cdf,

$F(M \mid C)=\Phi\left(\frac{100 \times C^{3.70}}{\left(\mathrm{BCF}_{m} \times \mathrm{LC}_{50}(\infty)\right)^{3.70}+C^{3.70}}\right)$

where $C$ is the given $\mathrm{Zn}$ concentration, and $\Phi(\bullet)$ is the cumulative standard normal distribution.

\subsection{Analysis of uncertainty}

Uncertainty arises from estimation of both exposure and effects. In order to quantify this uncertainty and its impact on the estimation of expected risk, we implemented a Monte Carlo simulation that includes input distributions for the parameters of the derived doseresponse function as well as for estimated exposure parameters. To test the convergence and the stability of the numerical output, we performed independent runs at $1,4,5$, and 10 thousand iterations with each parameter sampled independently from the appropriate distribution at the start of each replicate. Largely because of limitations in the data used to derive model parameters, inputs were assumed to be independently. The result shows that 5000 iterations are sufficient to ensure the stability of results. In this case, the numerical error on the 95th percentile is equal to $2 \%$. Sokal and Rohlf (1995) also indicated that more than 1000 replicate simulations gives Kolmogorov-Smirnov (K-S) 95\% confidence limits of approximately $\pm 4 \%$ on output distributions and should be sufficient to ensure reliable results. The simulation was implemented using@RISK
(Version 4.5, Professional Edition, Palisade Crop., USA).

\subsection{Model parameterization}

Parameterization of the model involved selecting data sets and deriving input distributions. Current literature was reviewed to develop probability distributions for the random variables appearing in the bioaccumulation model and dose-response model adopted. Source data of input variables appearing in Eqs. (5)-(8) and Eq. (10) were obtained from published studies by Chen (1984, 1989), Lee et al. (1996), Lin and Liao (1999), Chen and Lee (1999) and Liao et al. (2002a,b, 2003). Data were sorted by reported statistical measure, e.g., mean, standard deviation, standard error, etc. The data were divided into a minimum of 10 bins as equally as possible. Absolute and relative frequencies were calculated and distributions were plotted using bin midpoints. We used the chi-square $\left(\chi^{2}\right)$ and the $\mathrm{K}-\mathrm{S}$ statistics (Zar, 1999) to optimize the goodness-of-fit of distributions. We employed@RISK to analyze data and to estimate distribution parameters. The @ RISK generated $p$ values for the $\chi^{2}$ statistics and provided critical values of $D_{\max }$ for the $\mathrm{K}-\mathrm{S}$ statistics to estimate significant levels from 0.01 to 0.50 . For optimization, $P \geqslant 0.5$ considered good, $P=0.5-0.10$ was acceptable and $P<0.10$ was poor. The selected distribution type and parameters were based on statistical criteria, comparisons of distribution parameters, and visual interpretation of histograms. The implemented parameter probability distributions are summarized in Table 1 and described in the subsequent sections.

\subsubsection{Consumer-resource parameters: $f, g, \mu_{m}, r_{a}, \alpha, D$}

A normal distribution was determined to provide the best fit for the consumer-resource parameters of $f, g$, $\mu_{m}, r_{a}, \alpha$ (Table 1). The determination of half-saturation biomass for algae ingestion $(D)$, can be approximately obtained by fitting the Holling type II function of Eqs. (1) and (2) with known values of grazing rate of abalone $(g)$, death rate of abalone $\left(\mu_{m}\right)$ and growth rate of algae $\left(r_{a}\right)$ given in Table 1 , to the biomass observations for algae and abalone collected from three different abalone farms. Distributions were fitted to the polled data, and the log-normal distribution optimizing the $\mathrm{K}-\mathrm{S}$ fit was selected for $D$ (Table 1).

\subsubsection{Biokinetic parameters: $k_{1}, k_{2}, k_{1 a}, k_{2 a}, \mathrm{BCF}_{a}$, and $\mathrm{BCF}_{m}$}

Distributions were fitted to polled lab- and fieldderived biokinetic data obtained from different sources and the selected log-normal distributions had the acceptable $\chi^{2}$ fit and $\mathrm{K}-\mathrm{S}$ fit in that optimizations using either statistics yielded geometric mean (gm) and geometric standard deviation (gsd) (Table 1). 
Table 1

Input variables parameters values used to define distributions for Monte Carlo simulations (See Nomenclature for symbol descriptions)

\begin{tabular}{ll}
\hline Parameters & $\begin{array}{l}\text { Uncertainty/ } \\
\text { Variability }\end{array}$
\end{tabular}

\begin{tabular}{lc}
\hline \multicolumn{2}{l}{ Consumer-resource parameters } \\
$f\left(\mathrm{~g} \mathrm{~g}^{-1}\right)$ & $\mathrm{V}$ \\
$g\left(\mathrm{~g} \mathrm{~g}^{-1} \mathrm{~d}^{-1}\right)$ & $\mathrm{V}$ \\
$\mu_{\mathrm{m}}\left(\mathrm{d}^{-1}\right)$ & $\mathrm{V}$ \\
$r_{a}\left(\mathrm{~d}^{-1}\right)$ & $\mathrm{V}$ \\
$\alpha(\%)$ & $\mathrm{V}$ \\
$\mathrm{D}\left(\mathrm{g}^{-1}\right)$ & $\mathrm{V}$ \\
Toucheng & \\
Kouhu & \\
Anping &
\end{tabular}

$\mathrm{N}(3.500,0.810)$

$\mathrm{N}(0.250,0.050)$

$\mathrm{N}(0.286,0.170)$

$\mathrm{N}(0.038,0.013)$

$\mathrm{N}(0.346,0.146)$

LN (313.64, 1.200) $)^{\mathrm{b}}$

LN (343.04, 1.300)

LN $(205.82,1.100)$

Lab-derived biokinetic parameters

$k_{1}\left(\mathrm{ml} \mathrm{g}^{-1} \mathrm{~d}^{-1}\right) \quad \mathrm{U}$

$k_{2}\left(\mathrm{~d}^{-1}\right) \quad \mathrm{U}$

$k_{1 \mathrm{a}}\left(\mathrm{ml} \mathrm{g}^{-1} \mathrm{~d}^{-1}\right) \quad \mathrm{U}$

$k_{2 \mathrm{a}}\left(\mathrm{d}^{-1}\right)$

$\mathrm{U}$

Field-derived biokinetic parameters

$\mathrm{BCF}_{\mathrm{a}}\left(\mathrm{ml} \mathrm{g}^{-1}\right) \quad \mathrm{U}$

$\mathrm{BMF}_{\mathrm{m}}\left(\mathrm{g} \mathrm{g}^{-1}\right) \quad \mathrm{U}$

Dose-response parameters

$\mathrm{BCF}_{\mathrm{m}}\left(\mathrm{ml} \mathrm{g}^{-1}\right) \quad \mathrm{U}$

$\mathrm{LC}_{50}(\infty)\left(\mathrm{mgl}^{-1}\right) \quad \mathrm{U}$

Geochemical parameter

$C_{w}\left(\mu \mathrm{g} \mathrm{ml}^{-1}\right)$

Toucheng

Kouhu

Anping

LN (99.011, 1.288)

LN (0.390, 4.746)

LN (97.030, 1.292)

LN $(0.556,1.535)$

LN (635.362, 8.656)

LN (2.252, 2.064)

LN (264.053, 1.928)

$\mathrm{N}(1.080,0.127)$

LN $(0.127,1.310)$

LN $(0.055,1.700)$

LN $(0.059,1.770)$

a $\mathrm{N}(\mathrm{m}, \mathrm{S} . \mathrm{D}$.) represents normal distribution with mean $(\mathrm{m})$ and standard deviation (S.D.).

b LN (gm, gS.D.) represents lognormal distribution with geometric mean (gm) and geometric standard deviation (gS.D.).

\subsubsection{Geochemical parameter: $\mathrm{C}_{\mathrm{w}}$}

Distributions of water $\mathrm{Zn}$ concentrations in abalone pond $\left(C_{w}\right)$ were fitted to the polled field observations obtained from three assigned abalone farm locations and the selected log-normal distributions had the optimal $\mathrm{K}-\mathrm{S}$ and $\chi^{2}$ goodness-of-fit (Table 1).

\subsubsection{Dose-response parameters: $\mathrm{BCF}_{\mathrm{m}}$ and $\mathrm{LC}_{50}(\infty)$}

In applying dose-response relationships derived from experimental study, we must consider the limitations of the data and account for the inherent uncertainty that arises from a number of sources, including the limited number of observations and limited sample size within treatment sets. To account for this uncertainty, we constructed distributions for the input variables of $\mathrm{BCF}_{\mathrm{m}}$ and $\mathrm{LC}_{50}(\infty)$ of Hill dose-response function in Eq. (10). We determined log-normal and normal distributions for $\mathrm{BCF}_{\mathrm{m}}$ and $\mathrm{LC}_{50}(\infty)$, respectively (Table 1), and incorporated the distributions into the Monte Carlo simulation to obtain 2.5th- and 97.5th-percentiles as the $95 \%$ confidence interval for reconstructed dose-response profile. Uncertainty and/or variability were not considered for the reported Hill coefficient. This was unfortunate but unavoidable since the Hill coefficient from the published study was reported only as an average value. As a result, the risk curves and confidence limits reported here do not incorporate this source of uncertainty.

\subsection{Risk characterization}

Risk characterization is the phase of risk assessment where the results of the exposure and quantitative effects assessments are integrated to provide an estimate of risk for the population under study. In this case, it entails combining the exposures, measured as soft tissue concentrations from the various abalone farms, with the quantitative concentration-response relationship between tissue residue and associated mortality determined from the experimental studies.

Risk at a specific $\mathrm{Zn}$ concentration in abalone, $C_{m}$, can be calculated as the proportion of the abalone expected to have that tissue concentration multiplied by the conditional probability of abalone mortality, given concentration $C_{m}$. This results in a joint probability function (JPF) or exceedence profile, which describes the probability of exceeding the concentration associated with a particular degree of effect. Graphic display of the JPF also provides a means of assessing how alterations in ambient concentrations due to management efforts or natural attenuation would affect the risk assessment. This can be expressed mathematically as

$R\left(C_{m}\right)=F\left(C_{m}\right) F\left(M \mid C_{m}\right)$,

where $R\left(C_{m}\right)$ is the risk at a specific concentration $C_{m}$, $F\left(C_{m}\right)$ is the cdf of having tissue concentration $C_{m}$, and $F\left(M \mid C_{m}\right)$ is the conditional cdf of the mortality, given tissue concentration $C_{m}$.

A risk curve was generated from the cumulative distribution of simulation outcomes. Each point on the risk curve represents both the probability that the chosen proportion of abalone will be affected and also the frequency with which that level of effect would be exceeded. The $x$-axis of the risk curve can be interpreted as a magnitude of effect (a percentage of the given abalone expected to suffer the adverse effect), and the $y$-axis can be interpreted as the probability that an effect of at least that magnitude will occur. These probabilities are based on the current exposure data so at each point on the JPF we can also say "under current conditions, $x \%$ of abalone will be effected and that this proportion of abalone would be affected by $y \%$ of the current observations."

The overall expected risk for abalone may be computed as the sum of the risks for all possible $C_{m}$ s. Specifically, since the tissue $\mathrm{Zn}$ concentrations in abalone is distributed log-normally, and the responses follow Eq. (11), the overall expected risk, $\mathbf{E}[R]$, could be estimated as 
$\boldsymbol{E}[R]=F\left(\bar{C}_{m}\right) F\left(M \mid \bar{C}_{m}\right)$,

where $\mathbf{E}[\bullet]$ is the expectation operator and $\bar{C}_{m}$ is the mean concentration of $\mathrm{Zn}$ in abalone and can be written as

$\bar{C}_{m}=\frac{\int_{0}^{\infty}\left(\mathrm{LN}_{C_{m}}\left(\mu_{g}, \sigma_{g}\right)\right) C_{m} d C_{m}}{\int_{0}^{\infty} \mathrm{LN}_{C_{m}}\left(\mu_{g}, \sigma_{g}\right) d C_{m}}$,

and the cdfs of $F\left(\bar{C}_{m}\right)$ and $F\left(M \mid \bar{C}_{m}\right)$ can be expressed, respectively, as

$F\left(\bar{C}_{m}\right)=\Phi\left(\frac{\ln \bar{C}_{m}-\ln \mu_{g}}{\ln \sigma_{g}}\right)$,

and

$F\left(M \mid \bar{C}_{m}\right)=\Phi\left(\frac{100 \times \bar{C}_{m}^{3.70}}{\left(\mathrm{BCF}_{m} \times \mathrm{LC}_{50}(\infty)\right)^{3.70}+\bar{C}_{m}^{3.70}}\right)$,

where the lognormal probability density function (pdf), $\mathrm{LN}_{C_{m}}\left(\mu_{g}, \sigma_{g}\right)$, can be expressed as

$\mathrm{LN}_{\mathrm{C}_{\mathrm{m}}}\left(\mu_{g}, \sigma_{g}\right)=\frac{1}{\sqrt{2 \pi} C_{m} \ln \sigma_{g}} \exp \left[-\frac{1}{2}\left(\frac{\ln C_{m}-\ln \mu_{g}}{\ln \sigma_{g}}\right)^{2}\right]$,

where $\mu_{g}$ and $\sigma_{g}$ denote the geometric mean and geometric standard deviation of the lognormal distribution exposures, respectively.

A confidence interval for expected risk was determined on the basis of the 2.5 th and 97.5 th percentiles of the simulation results.

To assess growth endpoint, we use hazard quotient (HQ) to determine the potential growth risk as (USEPA, 2000),

$\mathrm{HQ}=\mathrm{PEC} / \mathrm{NOEC}$,

where PEC is the predicted environmental concentration expressed as pond water $\mathrm{Zn}$ concentration that inhibiting abalone growth and NOEC is the chronic no-observed effect concentration of toxicant reference value (TRV) expressed by most sensitive chronic endpoint, e.g., 28-day growth. If PEC were equal to a TRV then the HQ would be 1.0. Thus for HQ values greater than 1.0, some potential for inhibiting growth can be inferred. HQ values less than 1.0 indicate that the potential for inhibiting growth is low. Tsai et al. (2003) have conducted a growth toxicity bioassay for $H$. diversicolor supertexta exposed to Zn. A 28-day chronic toxicity study demonstrated that the highest $\mathrm{Zn}$ concentration that did not have an inhibiting effect (NOEC) on the abalone growth was $0.0625 \mu \mathrm{g} \mathrm{ml}^{-1}$.

\section{Results and discussion}

\subsection{Exposure assessment}

Fig. 2 illustrates the predicted pdfs of $\mathrm{Zn}$ contents in abalone and algae subject to the measured pdfs of pond water $\mathrm{Zn}$ concentrations from the three selected abalone farm locations. Probabilistic simulations of the biokinetic-consumer-resource bioaccumulation model produced skewed distributions of predicted $\mathrm{Zn}$ concentrations in abalone and algae. Percentile predictions of biomass of abalone and algae associated with $\mathrm{Zn}$ contents in abalone and algae could be determined from the cdfs that are derived from the corresponding pdfs shown in Fig. 2. Fig. 3 shows the box plots of interquartile and 50th-percentile predictions associated with whisker plots indicating 10th- and 90th-percentile predictions of $\mathrm{Zn}$ contents and biomass of abalone and algae in different abalone farms.

Compared with the field observations, median estimates of $\mathrm{Zn}$ in algae and abalone as well as the biomass of abalone and algae were generally less than measured mean values (Fig. 3). Measured algae biomasses are within the predicted interquartile, whereas the model underestimates the abalone biomasses (Fig. 3A). Three of six field observation data sets for each selected abalone farm of $\mathrm{Zn}$ in algae and abalone are within the predicted 25th- and 75th-percentile range, and five of them all fall within the 10th- and 90th- percentile range (Fig. 3B). Thus, applying the Monte Carlo technique to the proposed exposure model generated probabilistic estimates of $\mathrm{Zn}$ concentrations in algae and abalone as well as biomass that were favorably consistent with field data. Relative to minimum and maximum field data, however, lower and upper probabilistic percentile predictions were more conservative. It is evident that the modeling framework and the distributional parameters and assumptions in the model are appropriate for estimating algae and abalone exposed to waterborne $\mathrm{Zn}$.

\subsection{Estimation of concentration-response function}

The Hill model and a 5000 Monte Carlo simulation provided an adequate fit for the data ( $\chi^{2}$ goodness-offit, $P>0.5)$. Based on this concentration-response function (Fig. 4), the calculated median effective concentration $\left(\mathrm{EC}_{50}\right)$ is $285 \mu \mathrm{g} \mathrm{g}^{-1}$ dry wt. with $95 \%$ confidence interval of approximately 214 and $351 \mu \mathrm{g} \mathrm{g}^{-1}$ dry wt. of whole-body abalone on a dry-weight basis. A threshold value can also be estimated on the basis of the fitted dose-response model. The $\mathrm{EC}_{10}$ value calculated from the fitted dose-response model is $158 \mu \mathrm{g} \mathrm{g}^{-1}$ dry wt. of whole-body abalone with a 95\% confidence interval of 121 and $194 \mu \mathrm{g} \mathrm{g}^{-1}$ dry wt. USEPA (USEPA, 2000) recommended that $\mathrm{EC}_{10}$ can be used as a surrogate threshold of regulatory endpoint in probabilistic 


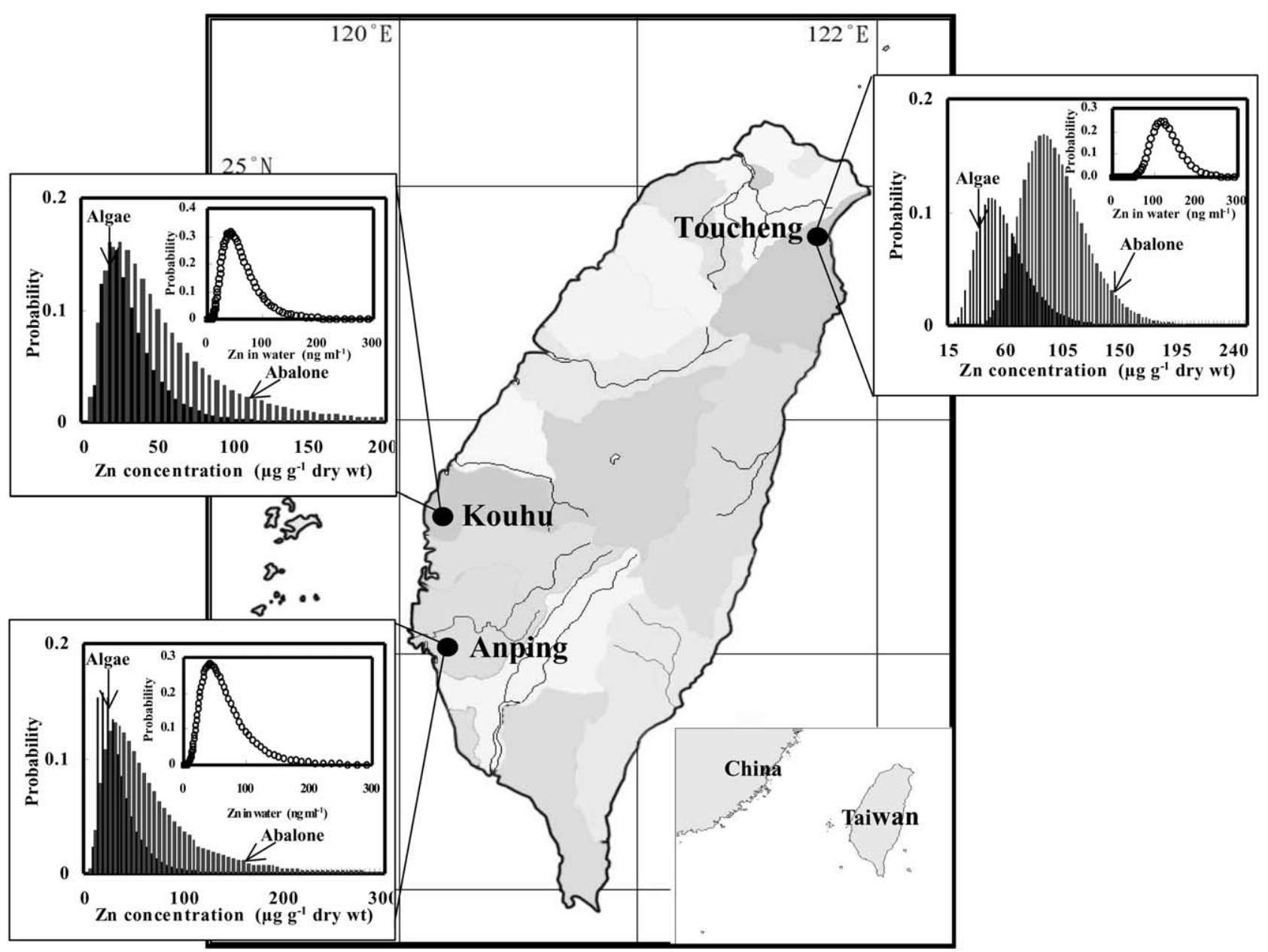

Fig. 2. Overall display of probabilistic distributions of predicted $\mathrm{Zn}$ concentrations in abalone $H$. diversilor supertexta and red algae $G$. tenuisipitata var. lilu subject to measured water $\mathrm{Zn}$ concentration at three selected abalone farm locations.

ecological risk assessment. In view of Fig. 3B, the distributions of $\mathrm{Zn}$ concentration in soft tissue of abalone almost entirely below the threshold value of derived $\mathrm{EC}_{10}\left(158 \mu \mathrm{g} \mathrm{g}^{-1}\right.$ dry wt.), suggesting that waterborne $\mathrm{Zn}$ dose not appear to pose a significant health risk to aquacultural abalone under field conditions at current environmental concentrations.

\subsection{Risk estimates}

The point estimates of expected exceedence risk of mortality for abalone in three different abalone farm locations are given in Table 2 in that we define risk as the percentage of the abalone that is expected to suffer mortality. The point estimates were calculated from Eq. (13) and ignore the uncertainty associated with estimate of concentration-response parameter of Hill coefficient. Confidence intervals calculated from the 2.5th and 97.5th quantiles of the Monte Carlo simulation results are also shown in Table 2. These ranges represent the uncertainty in expected risk estimates with both the inherent variability and uncertainty in exposure and concentration-response parameter estimates are considered. The confidence intervals for the expected risk are relatively narrow. Table 2 suggests that the relative high risk for abalone farms in Toucheng is alarming since nearly half $(46 \%)$ of abalone are expected to fail to survive because of their exposure to waterborne $\mathrm{Zn}$.

Risk curves shown in Fig. 5 indicate the estimated probabilistic of effects of differing magnitude for abalone for each selected abalone farm locations. The plotted probabilities, calculated from the outcome of the Monte Carlo simulation followed a JPF shown in Eq. (12) describing the exceedence cdfs (Fig. 5) associated

Table 2

Expected risk of mortality endpoint. Confidence intervals were computed from 2.5th- and 97.5th-percentiles of 5000 Monte Carlo simulations

\begin{tabular}{lll}
\hline Study site & Expected risk & $95 \%$ confidence interval \\
\hline Toucheng & 0.461 & $0.455-0.478$ \\
Kouhu & 0.364 & $0.356-0.388$ \\
Anping & 0.288 & $0.286-0.293$ \\
\hline
\end{tabular}



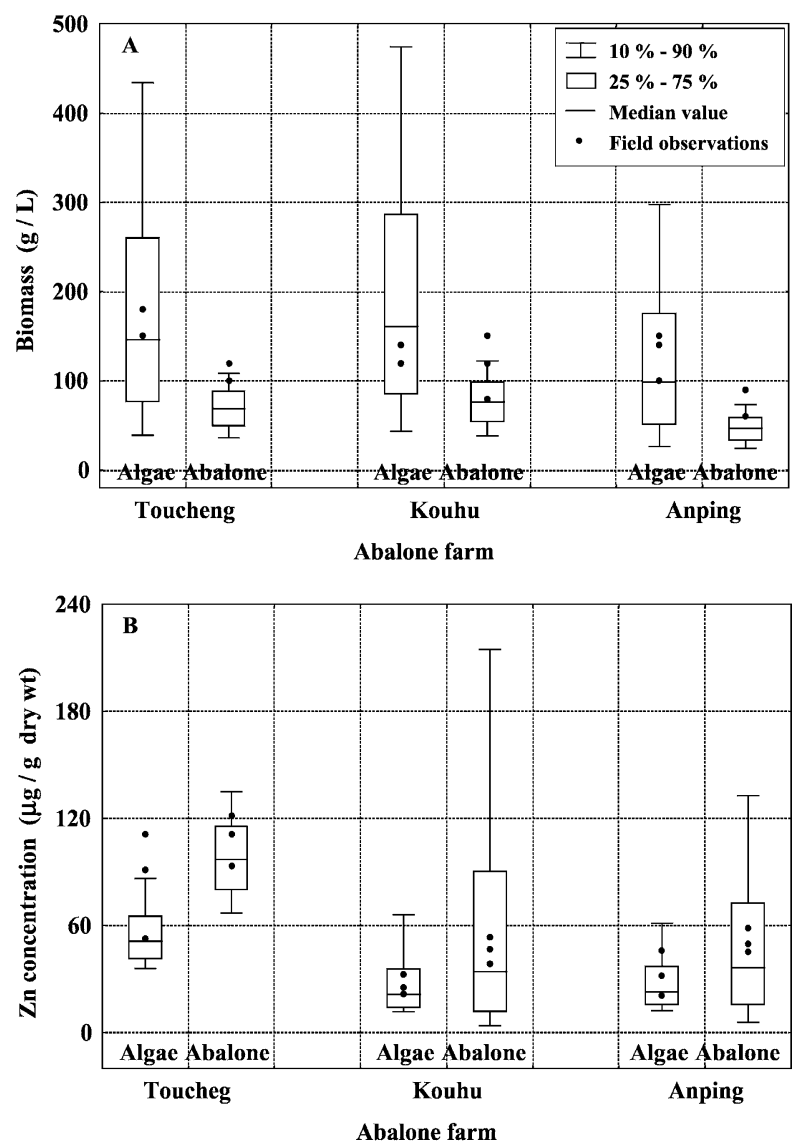

Fig. 3. Box and whisker plot representations of (A) biomass and (B) $\mathrm{Zn}$ concentration in abalone $H$. diversilor supertexta and red algae $G$. tenuisipitata var. lilu at three selected abalone farm locations. Box and whisker plots are used to represent the uncertainty in biomass and $\mathrm{Zn}$ level estimates.

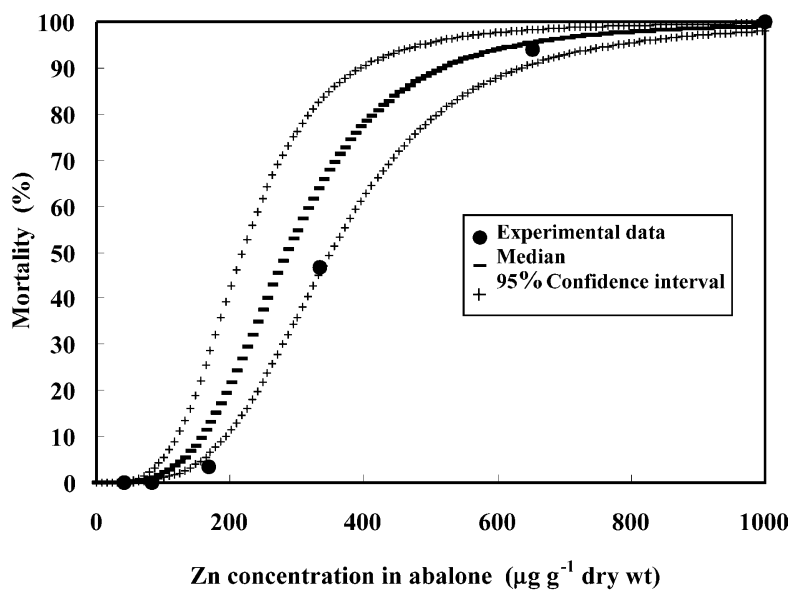

Fig. 4. Reconstructed concentration-response curve with $95 \%$ confidence interval for relationship between abalone mortality and $\mathrm{Zn}$ concentration in abalone.

with a particular degree of effect (Fig. 4), take into account the uncertainty in estimating risk derived from variability and uncertainty in model parameters. For Toucheng abalone farm, the probability that $25 \%$ or
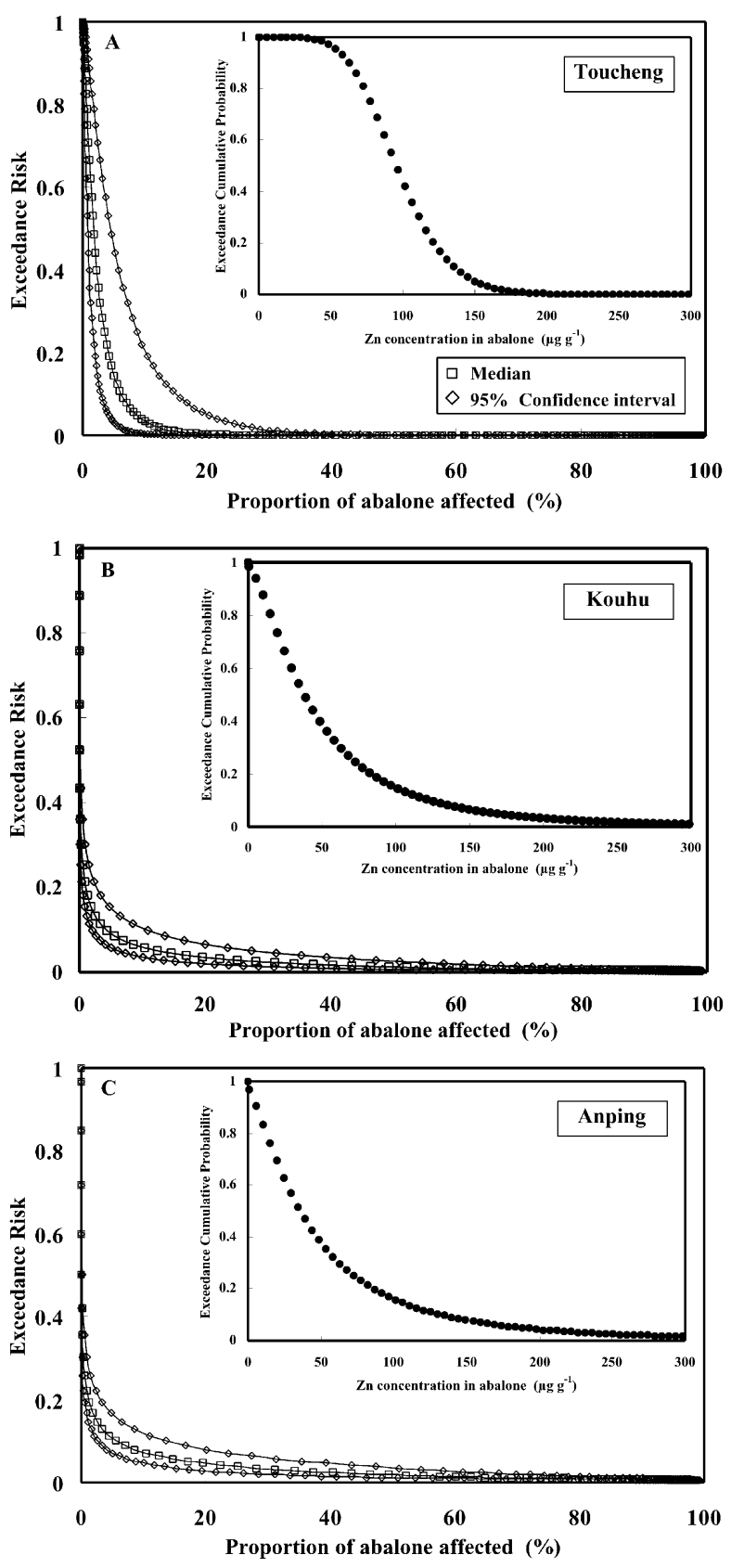

Fig. 5. Exceedence risk (mortality) functions with $95 \%$ confidence interval for selected abalone farms at (A) Toucheng, (B) Kouhu, and (C) Anping, respectively. Inset shows the exceedence cumulative dis-

more of the abalone is affected (risk $=0.25$ ) is approximately $4 \%$, with $95 \%$ confidence interval of 2 and $9 \%$, i.e., the probability is 0.25 that at least $4 \%$ of abalone from Toucheng abalone farms will not survive; whereas the probability is 0.5 that at least $2 \%$ of abalone will suffer mortality. Furthermore, for Kouhu and Anping abalone farms, the probability is 0.25 that at least $1 \%$ mortality for abalone.

Fig. 6 shows that for Kouhu and Anping abalone farms, a $90 \%$ probability or less experiencing a HQ less 


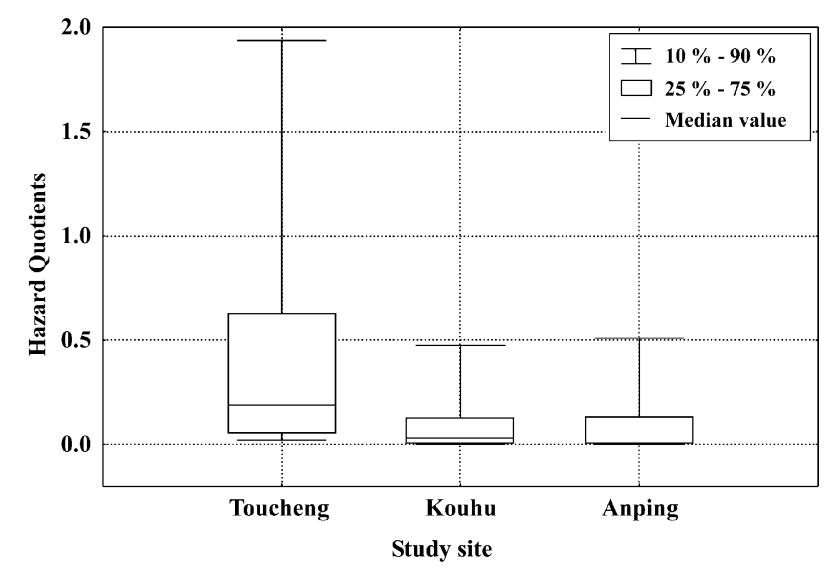

Fig. 6. Box and whisker plot representations of hazard quotients for abalone growth risk estimates.

than 1 for abalone exposed to waterborne $\mathrm{Zn}$, indicating that these probability distributions are acceptable; whereas the 90th-percentile HQ is larger than 1 for Toucheng abalone farms, indicating a conservatism potential for inhibiting abalone growth is inferred.

\subsection{Implications}

Our analysis indicates no significant risk of survival and growth for abalone in Kouhu and Anping, yet risk of growth particularly pronounced for the Toucheng abalone farms. Our analysis addresses solely the risk associated with $\mathrm{Zn}$ exposure, although other metal contaminants were measured in the tissue of abalone (Richardson, 2001; Wang and Ke, 2002). We specifically chose to quantify adverse effects related to $\mathrm{Zn}$ exposure because the weight of available data including exposure and toxicological data from experimental studies strongly supports the choice of $\mathrm{Zn}$ as our study metal to carry out the risk assessment. Furthermore, if the concentration of some metal contaminants other than $\mathrm{Zn}$ is uncharacteristically high for a give abalone population, the possibility of a significantly increased risk unaccounted for by our model should be investigated.

The probabilistic methods used show that field data or experimentally derived values may hide significantly different levels of conservatism in relation to the uncertainty and variability present in each input parameters. Variability and uncertainty in model inputs were addressed using conservative assumptions, a range of abalone farm scenarios, and probabilistic analysis. The analysis does not reflect all source of uncertainty. USEPA (USEPA, 1998) and Voit and Schbauer-Berigan (1998) pointed out that probabilistic analysis does not account for structural errors in the model or inaccurate distributions of input variables. Although, assuming independence among inputs is a common assumption in probabilistic analyses for initial analyses and when data sufficient to derive correlation coefficients are unavailable, biases may result that account for some of the overprediction.

Presumably, centers of distribution are more realistic than tails and, thus, the analysis emphasizes interquartile predictions (Burmaster and Hull, 1997; Edelmann and Burmaster, 1997). Fortunately, available field data allow validation over the range of model outputs, including the upper percentile predictions. The model provides preliminary estimates of such statistics and this information is valuable because it can be used to guide future analysis and data collection efforts. In fact, through requiring more resources and skills, a Monte Carlo technique carried out was very informative since it revealed the degree of conservatism and took into account the reliability of results. Given the scarcity of data, most of the probability distributions were based on limited observations from abalone farms, and this may be a limit to the validity of the case presented.

Risk assessors bring needed expertise to a risk assessment team. Interested parties, e.g., municipal governments, environmental groups, or small-business owners may provide important information to risk assessors. Risk assessors and interested parties describe what they can provide to the risk manager, where problems are likely to occur, and where uncertainty may exist. To give greater emphasis to these interactions, the ecological risk assessment could be modified to include interested parties in the risk planning at the beginning of the process and communicating with interested parties in the risk management following the risk assessment.

The present analysis shows that exposure and concentration-response profiles are important components in evaluating the risk. We have represented a novel approach in that a biokinetic-consumer-resource accumulation model was coupled with dose-response curves to assess abalone survival endpoint. On the other hand, the growth endpoint was assessed by hazard quotients featuring measured water $\mathrm{Zn}$ level and no-observed effect concentration. With proper application of risk communication, we can channel this legitimate concern into actions that will result in stricter water quality regulation. The end result of such action will improve the water quality, which will benefit the health of the aquacultural species and the health of the people who eat them.

Our previous published toxicity bioassay data can be used extensively in the emerging field of ecological risk assessment. Three basic categories of factors: exposure, toxicokinetics, and toxicodynamics, interact to determine the responses in bioassays. The concentrationresponse relationships can be viewed as integral in an overall scheme of ecological risk assessment involving bioaccumulation modeling. Concentration-response relationships will allow the substantial progress that environmental toxicology of $\mathrm{Zn}$ to abalone has made in our earlier work to continue without losing touch with 
either the exposure-based information or the fieldbased observations of adverse responses and residue monitoring data.

\section{Conclusions}

We present a novel risk assessment technique that integrates predicted soft tissue concentrations of $\mathrm{Zn}$ with a reconstructed dose-response relationship and employs a joint probability function incorporating exposure and concentration-response profiles to characterize the survival and growth risks for pond abalone Haliotis diversicolor supertexta. Our risk analysis demonstrates that the expected risks of mortality for abalone were estimated as 0.46 (Toucheng), 0.36 (Kouhu), and 0.29 (Anping). The predicted 90th-percentiles of hazard quotient for potential growth risk were estimated as 1.94 (Toucheng), 0.47 (Kouhu), and 0.51 (Anping). Bioaccumulation of $\mathrm{Zn}$ seems unlikely to result in toxicity to pond abalone. Using the present risk assessment method, we conclude that waterborne $\mathrm{Zn}$ does not appear to pose significant risks of survival and growth to pond abalone in Kouhu and Anping. A relative high growth risk in Toucheng, however, is alarming.

It is our opinion that the incorporation of probabilistic analysis into evaluation of exposure and concentration-response relationship greatly improves our ability to appraise the range of possible exposure scenarios and environmental risk to aquacultural species and human who consume contaminated fish and mollusks. Probabilistic risk assessment will substantially reduce the compounded conservatism that is inherent in risk assessment that relies on conservative point value estimates for all biokinetic- consumer-resource-, and toxicological effects-related parameters.

\section{References}

Bourne, D.W.A., 1995. Mathematical Modeling of Pharmackinetic data. Technomic Publishing Company, Inc, Lancaster, Penn.

Burmaster, D.E., Hull, D.A., 1997. Using lognormal distributions and lognormal probability plots in probabilistic risk assessment. Human and Ecological Risk Assessment 3, 235-255.

Chen, H.C., 1984. Studies on the aquaculture of small abalone, Haliotis diversicolor supertexta, in Taiwan. In: Liao, I.C., Hirano, R. (Eds.), Proceedings of ROC-Japan Symposium on Mariculture, Vol. 1. Tungkang Marine Laboratory, Pintung, Taiwan, pp. 143-159.

Chen, H.C., 1989. Farming the small abalone, Haliotis diversicolor supertexta, in Taiwan. In: Hahn, K.O. (Ed.), Handbook of Culture of Abalone and Other Marine Gastropods. CRC Press, FL, USA, pp. 265-283.

Chen, J.C., Lee, W.C., 1999. Growth of Taiwan abalone Haliotis diversicolor supertexta fed on Gracilaria tenuistipitata and artificial diet in a multiple-tier basket system. Journal of Shellfish Research 18, 627-635.

Conroy, P.T., Hunt, J.W., Anderson, B.S., 1996. Validation of a short-term toxicity test endpoint by comparison with longer-term effects on larval red abalone Holiotis rufescens. Environmental Toxicology and Chemistry 15, 1245-1250.

Edelmann, K.G., Burmaster, D.E., 1997. Are all distribution of risk with the same 95th percentile equally acceptable? Human and Ecological Risk Assessment 3, 223-234.

Hahn, K.O., 1989. Biotic and abiotic factors affecting the culture of abalone. In: Hahn, K.O. (Ed.), Handbook of Culture of Abalone and Other Marine Gastropods. CRC Press, FL, USA, pp. 113-283.

Knauer, K., Behra, R., Sigg, L., 1997. Effects of free $\mathrm{Cu}^{2+}$ and $\mathrm{Zn}^{2+}$ ions on growth and metal accumulation in freshwater algae. Environmental Toxicology and Chemistry 16, 220-229.

Lalonde, R.L., 1992. Pharmacodynamics. In: Evans, W.E., Schentag, J.J., Jusko, W.J. (Eds.), Applied pharmacokinetics. Lip-pincott Williams and Wilkins, New York, pp. 4-33.

Lee, C.L., Chen, H.Y., Chuang, M.Y., 1996. Use of oyster, Crassostrea gigas, and ambient water to assess metal pollution status of the Charting coastal area, Taiwan, after the 1986 green oyster incident. Chemosphere 33, 2505-2532.

Liao, C.M., Chen, B.C., Tsai, J.W., Chen, J.W., Chou, Y.H., Ling, M.P., 2003. A parsimonious AUC-based biokinetic method to estimate relative bioavailable zinc to abalone Haliotis diversicolor supertexta. Aquaculture.

Liao, C.M., Lin, M.C., Chen, J.S., Chen, J.W., 2002a. Linking biokinetics and consumer-resource dynamics of zinc accumulation in pond abalone Haliotis diversicolor supertexta. Water Research 36, 5102-5112.

Liao, C.M., Chen, B.C., Lin, M.C., Chiu, H.M., Chou, Y.H., $2002 b$. Coupling toxicokinetics and pharmacodynamics for predicting survival of abalone (Haliotis diversicolor supertexta) exposed to waterborne zinc. Environmental Toxicology 17, 478-486.

Liao, C.M., Lin, M.C., 2001. Toxicokinetics and acute toxicity of waterborne zine in abalone (Haliotis diversicolor supertexta Lischke). Bulletin of Environmental Contamination and Toxicology 66, 597-602.

Lin, M.C., Liao, C.M., 1999. ${ }^{65} \mathrm{Zn}(\mathrm{II})$ accumulation in the soft tissue and shell of abalone Haliotis diversicolor supertexta via the alga Gracilaria tenuistipitata var. liui and the ambient water. Aquaculture 178, 89-101.

Richardson, C.A., 2001. Oceanography and marine biology. Oceanography and Marine Biology 39, 103-164.

Singhagraiwan, T., Doi, M., 1993. Seed production and culture of a tropical abalone, Haliotis asinine Linne. The Eastern Marine Fisheries Development Center. Thailand 31.

Sokal, R.R., Rohlf, F.J., 1995. Biometry, third ed. WH Freeman and Company, New York, USA.

Tsai, J.W., Chou, Y.H., Chen, B.C., Liang, H.M., Liao, C.M., 2003. Growth toxicity bioassays of abalone Haliotis diversicolor supertexta exposed to waterborne zinc. Bulletin of Environmental Contamination and Toxicology.

US EPA, 1998. Guidelines for ecological risk assessment. EPA/630/ R-95/002F, US Environmental Protection Agency, Washington, DC.

US EPA, 2000. Technical progress report of the implementation plan for probabilistic ecological assessments: aquatic systems. Meeting scheduled for April 6-7. US Environmental Protection Agency, Washington, DC.

Voit, E.O., Schubauer-Berigan, M.K., 1998. Canonical modeling as a unifying framework for ecological and human risk assessment. In: Newman, M.C., Strojan, C.L. (Eds.), Risk Assessment: Logic and Measurement. Ann Arbor Press, Chelsea, MI, USA, pp. 101-139.

Wang, W.X., Ke, C.H., 2002. Dominance of dietary intake of cadmium and zinc by two marine predatory gastropods. Aquatic Toxicology 56, 153-165.

Zar, J.H., 1999. Biostatistical Analysis, fourth ed. Prentice-Hall, Inc, New Jersey, USA. 